\title{
REPRESENTASI KEHIDUPAN MULTIKULTURAL DALAM TIGA CERITA BERSAMBUNG PEMENANG SAYEMBARA MENGARANG MAJALAH FEMINA 2012
}

\author{
Kusmarwanti \\ FBS Universitas Negeri Yogyakarta \\ Email: kusmarwanti@gmail.com
}

\begin{abstract}
ABSTRAK
Penelitian ini bertujuan untuk mendeskripsikan kondisi sosial budaya, interaksi budaya dengan pendatang, dan respon tokoh terhadap pendatang yang menunjukkan adanya kehidupan multikultural dalam tiga cerita bersambung pemenang sayembara mengarang majalah Femina tahun 2012. Hasil penelitian ini adalah sebagai berikut. Pertama, tiga cerita bersambung pemenang sayembara mengarang Femina 2012 mengangkat kehidupan suku Dayak di Kalimantan, serta suku Bajo dan suku Seasea di Sulawesi. Kedua, ketiga cerita ini menampilkan pendatang dalam sukunya, yang sekaligus menunjukkan adanya kehidupan multikultural, yaitu perusahaan kayu yang mengambil keuntungan dari alam suku Dayak, penulis yang peduli dengan masalah pendidikan anak-anak suku Bajo, dan LSM yang bergerak di bidang sanitasi dan air yang akan melaksanakan program penyediaan air untuk suku Seasea. Ketiga, tokoh dalam ketiga cerita bersambung tersebut menunjukkan respon yang berbeda-beda dengan pendatang yang masuk ke dalam suku mereka, yaitu suku Dayak menunjukkan sikap terpengaruh dan melawan, serta suku Bajo dan Seasea menunjukkan sikap yang kooperatif untuk menyelesaikan permasalahan mereka.
\end{abstract}

Kata kunci: kehidupan multikultural, pendatang, cerita bersambung Femina

\section{MULTICULTURAL LIFE REPRESENTATION IN THREE SERIALS WINNERS OF THE 2012 FEMINA MAGAZINE WRITING CONTEST}

\begin{abstract}
This study aimed to describe the social and cultural conditions, cultural interaction of immigrant, and character's response to them that show a multicultural life in three serials of writing contest winner of Femina Magazine in 2012. The results of this study are as follows. First, the three serials exposed the life of Dayak tribe in Kalimantan Borneo, Bajo and Seasea tribe in Sulawesi. Secondly, the three serials was featuring immigrant in their life, which also indicates a multicultural life. The immigrant are the company that take advantage of Dayak's natural resources, writer who are concerned with education issues in Bajo children, and $\mathrm{NGO}$ who are concerned with sanitation and water and willing to provide them to Seasea tribe. Third, the characters in the serials show different responses to immigrants. Dayak tribe was affected and showed resistance, Bajo and Seasea tribes demonstrate a cooperative attitude to solve their problems.
\end{abstract}

Keywords : multicultural life, immigrants, Femina's serials

\section{A. PENDAhuluan}

Karya sastra merupakan respon pengarang terhadap berbagai peristiwa yang ada di sekitarnya. Di Indonesia, pengarang yang lahir dari berbagai budaya yang berbeda pun turut memperkaya lahirnya karya sastra dengan aspek multikultural yang dominan. Dalam hal ini bisa disebut berbagai karya sastra yang lahir dengan latar budaya Minangkabau, Jawa, Bali, Dayak, selain latar budaya kolonial yang tampak dalam beberapa karya sastra pada masa Balai Pustaka.

Terkait dengan hal ini, Mahayana (2008) menyatakan bahwa sastra merupakan bagian 
dari kebudayaan, di mana ia dihasilkan melalui proses panjang kegelisahan dan pemikiran sastrawannya yang tidak terlepas dari berbagai persoalan yang dalam konteks multikultural. Karena itu, karya sastra tidak hanya dapat diperlakukan sebagai dokumen sosial yang menggambarkan corak individu di dalam interaksinya dengan sebuah kelompok masyarakat atau suku bangsa, tetapi juga dapat dimaknai sebagai representasi budaya yang melahirkan, membesarkan, dan melingkarinya. Dalam karya sastra, unsur multikultural tersebut muncul dalam berbagai unsur, baik alur cerita, tokoh cerita, latar cerita, maupun bahasa.

Cerita bersambung pemenang sayembara mengarang yang diselenggarakan majalah Femina tahun 2012 merepresentasikan unsur multikulturalisme ini. Karya-karya tersebut adalah "Ulin" karya Anindita Siswanto Thaif sebagai pemenang pertama, "Rumah Perahu" karya Erni Aladjai sebagai pemenang kedua, dan "Sebelum Malam di Seasea" karya Erni Aladjai sebagai pemenang ketiga.

Multikultural menjadi isu yang mendasar dalam ketiga cerita bersambung tersebut. Adanya unsur multikultural dalam cerita bersambung tersebut diperkuat dengan pendapat Leila S. Chudori sebagai ketua juri sayembara yang menyatakan bahwa ketiga pemenang yang terpilih mengolah cerita dengan unsur budaya lokal yang kuat (Femina, 2012). Cerita bersambung "Ulin" mengangkat budaya Dayak yang harus dihadapkan pada budaya modern pada masyarakat peladang di pedalaman. Cerita bersambung "Rumah Perahu" mengangkat budaya Makasar, suku Bajo, dan budaya Eropa. Sementara itu, cerita bersambung "Sebelum Malam di Seasea" mengangkat budaya suku Seasea yang terletak di Kecamatan Luwuk Timur, Kabupaten Banggai, Sulawesi Tengah. Pengarang menghadirkan unsur multikultural melalui konflik, tokoh, dan latar cerita yang khas.

Interaksi antarbudaya di tengah keberagaman tradisi menjadi prioritas dalam studi multikulturalisme. Dalam tiga cerita bersambung ini, interaksi antarbudaya dilakukan dengan para pendatang, yaitu suku Dayak dengan perusahaan kayu yang memiliki kepentingan ekonomi, suku Bajo dengan penulis yang peduli dengan masalah pendidikan dan orang asing yang peduli dengan alam, dan suku Seasea dengan pendatang berupa LSM yang bergerak dalam bidang sanitasi dan air. Para pendatang ini membawa budaya baru. Respon yang ditunjukkan anggota suku pun beragam.

Dengan latar belakang ini, penelitian ini difokuskan pada representasi multikulturalisme dalam ketiga cerita bersambung tersebut, yang tampak pada kondisi sosial budaya, interaksi budaya dengan pendatang, dan respon tokoh terhadap pendatang yang menujukkan kehidupan multikultural. Permasalahan tersebut dibahas dengan teori sosiologi sastra.

\section{B. METODE}

Jenis penelitian ini adalah penelitian kualitatif. Hal ini didasarkan pada data dalam penelitian ini adalah berupa teks tulis, yaitu cerita bersambung pemenang sayembara mengarang majalah Femina tahun 2012. Pendekatan yang digunakan dalam penelitian ini adalah content analysis. Peneliti menganalisis teks novel secara cermat dan mendalam. Selanjutnya, data dideskripsikan sesuai dengan aspek kajian yang difokuskan dalam penelitian ini.

Sumber data ini adalah cerita bersambung pemenang sayembara mengarang majalah Femina tahun 2012. Cerita bersambung "Ulin" dan "Rumah Perahu" didapatkan dari www. femina.co.id, sedangkan "Sebelum Malam di Seasea" berupa naskah versi pdf dari penulisnya (Erni Aladjai).

Pengumpulan data dilakukan dengan cara membaca ketiga cerita bersambung tersebut secara berulang-ulang sehingga ditemukan data yang relevan. Instrumen penelitian adalah peneliti sendiri. Proses pencatatan (recording) dilakukan dengan menggunakan kartu data. Teknik ini digunakan untuk mengetahui kondisi sosial budaya yang menunjukkan adanya kehidupan multikultural, interaksi budaya dengan pendatang, dan respon tokoh terhadap pendatang dalam tiga cerita bersambung pemenang sayembara mengarang majalah Femina tahun 2012.

Teknik analisis data yang digunakan adalah analisis deskriptif kualitatif. Data-data tersebut dikelompokkan berdasarkan permasalahan, ditabulasikan, dijelaskan secara deskriptif kualitatif, kemudian dilakukan inferensi dengan memperhatikan aspek permasalahan dan temuan 
data selama proses pembacaan. Selanjutnya, data ditafsirkan dengan teori sosiologi sastra.

Keabsahan data diuji dengan validitas semantik, intrarater, dan interrater Validitas semantik digunakan dengan mengaitkan tulisan dengan interpretasi makna dan konteks yang melingkupnya. Intrarater dilakukan dengan membaca ketiga cerita bersambung tersebut secara cermat dan berulang-ulang sehingga ditemukan data yang sesuai dengan pokok kajian. Interrater dalam penelitian ini adalah pembimbing, Prof. Dr. Suminto A. Sayuti, yang berkecimpung dalam dunia sastra, serta rekan dosen lain yang termasuk dalam bidang terkait.

\section{HASIL DAN PEMBAHASAN}

Pada bagian ini akan dipaparkan kondisi sosial budaya yang melatari ketiga cerita bersambung pemenang sayembara mengarang majalah Femina tahun 2012, serta interaksi budaya dengan pendatang dan respon tokoh terhadap pendatang.

\section{Kondisi Sosial Budaya Tiga Cerita Ber- sambung Pemenang Sayembara Menga- rang Majalah Femina 2012}

Tiga cerita bersambung pemenang sayembara mengarang majalah Femina tahun 2012 memiliki latar budaya yang menunjukkan kondisi sosial budaya yang berbeda-beda. Cerita bersambung "Ulin" karya Anindita Siswanto Thaif mengangkat latar budaya Dayak. Cerita bersambung "Rumah Perahu" karya Erni Aladjai mengangkat latar budaya suku Bajo di Pulau Kalupapi, di Teluk Banggai, Sulawesi Tengah. Cerita bersambung "Sebelum Malam di Seasea" karya Erni Aladjai mengangkat latar budaya suku Seasea di Pulau Peling, Banggai, Sulawesi Tengah.

Suku Dayak memiliki ketergantungan pada ladang dan hutan. Mereka menjadikan alam sebagai sumber makanan dan obat-obatan. Mereka menggunakan tanda-tanda alam untuk berladang. Mereka juga sering menggunakan nama tumbuhan atau binatang untuk nama orang. Nama "Ulin" sebagai judul cerita dan nama tokoh utama cerita merupakan salah satu nama yang diambil dari nama pohon. Menurut Uluk (2001:16), ulin merupakan kayu yang biasa digunakan oleh masyarakat Dayak seba- gai tiang rumah. Kayu ulin ini kuat, tahan air, tidak diserang serangga, dan tidak mudah lapuk. Bahkan, kayu ulin ini dapat bertahan sampai ratusan tahun. Sifat kuat kayu ini digunakan untuk menggambarkan sifat Ulin yang keras kepala, dari sudut pandang Tambi. Selain itu, bagi masyarakat Dayak, ladang dan hutan menjadi tempat mewariskan ilmu kepada generasinya (Uluk dkk., 2001:57). Hal ini pun dilakukan Tambi pada Ulin. Ia mengajari Ulin dengan keterampilan berladang dan berburu di hutan.

Sebagaimana suku Dayak, suku Seasea dalam cerita bersambung "Sebelum Hujan di Seasea" merupakan salah satu suku terasing dan primitif di kepulauan ini yang menggantungkan hidup dengan hasil ladang dan hutan. Kondisi daratan di pulau Peling banyak merupakan kawasan pegunungan yang ditumbuhi pepohonan tinggi dan hutan yang cukup lebat. Mereka hidup tergantung dengan alam ini. Mereka menanam talas atau ubi yang merupakan makanan pokoknya. Tanaman talas ini memiliki nilai sakral. Menurut legenda setempat, tanaman talas diciptakan dalam waktu yang bersamaan dengan keberadaan manusia pertama di Seasea. Oleh para leluhur, tanaman ini dipindahkan ke ladang-ladang mereka hingga menjadi tanaman pokok komunitas Seasea (Alwi, 2010). Dalam cerita "Sebelum Hujan di Seasea" makanan ini disebut keladi. Keladi dan talas merupakan jenis makanan ubi-ubian.

Daerah pegunungan dalam suku Seasea berimbas pada medan yang tidak mudah. Jalan naik turun dengan fasilitas yang sangat terbatas. Dalam cerita hal ini tampak dalam perjalanan Farina ke pasar yang harus ditempuh dengan berjalan kaki turun naik bukit dengan jarak tempuh $15 \mathrm{~km}$. Di pasar itulah mereka melakukan barter atau saling tukar barang untuk memenuhi kebutuhan mereka. Dalam suasana barter jugalah Farina bertemu Mikus hingga mereka berkenalan dan menikah.

Berbeda dengan suku Dayak dan Seasea yang bergantung pada hasil ladang dan hutan, suku Bajo tergantung pada laut. Orang Bajo hidup di atas air dan menggunakan perahu dan leppa (perahu beratap) sebagai alat transportasi. Mereka hidup dengan mengembara secara nomaden atau berpindah-pindah. AhimsaPutra (2006:188) menyatakan bahwa pola hidup 
mengembara ini membuat orang-orang Eropa menyebut mereka sebagai sea gypsies (gipsy laut) atau sea nomads (pengembara laut).

Laut merupakan tempat masyarakat Bajo menggantungkan hidup. Dengan mencari hasil laut, mulai dari ikan hingga akar bahar, orang Bajo dapat terus bertahan dengan pola hidupnya hingga sekarang (Soesangobeng, Zacot, melalui Ahimsa Putra, 2006:188). Dalam cerita bersambung "Rumah Perahu" hal ini tampak pada aktivitas perempuan-perempuan Bajo menjemur teripang, kerang mata tujuh, dan ikan asin. Ketergantungan pada hasil laut juga tampak pada aktivitas Mbo Nuni memotong sirip ikan gorango (ikan hiu), serta membuat kima dan dendeng ikan duyung. Untuk memenuhi kebutuhannya, orang-orang suku Bajo juga berinteraksi dengan orang-orang darat untuk saling bertukar makanan (barter).

Suku Dayak, Bajo, dan Seasea memiliki kepercayaan pada sesuatu yang selalu dikaitkan dengan alam tempat mereka bergantung. Dalam hutan yang dihuni suku Seasea, ada banyak pohon yang rimbun dan binatang, seperti burung. Bagi masyarakat Seasea, burung gagak hitam merupakan pertanda musibah kematian (Alwi, 2010). Dalam cerita, burung hitam muncul di hadapan Malika sesaat sebelum ia menyaksikan Mikus menyabetkan sondang atau parang ke tubuh Farina yang memuncratkan darah ke mana-mana hingga meninggal.

Jika suku Seasea mengaitkan pertanda buruk dengan burung gagak hitam, maka suku Dayak mengaitkan pertanda buruk dengan seekor ular dan burung elang. Seekor ular dalam cerita hadir melalui mimpi Tambi. Ia bermimpi seekor ular bertamu ke pondok Ulin dan berdiam di bawah dipan. Mimpi ini disertai pertanda berupa seekor elang yang terbang rendah melintasi pondok Tambi. Mimpi ini merupakan pertanda buruk bagi nasib Andau, suami Ulin, yang memilih bergabung dengan pendatang demi uang. Bagi masyarakat Dayak, mimpi di malam hari merupakan pertanda yang diberikan Ranying Hattala, para dewa, para malaikat, dan sangiang kepada manusia (Riwut melalui Bungas, 2012).

Ranying Hattala Langit merupakan salah satu Tuhan orang Dayak. Masyarakat Dayak mempunyai mitos tentang keberadaan bumi, langit, dan makhluk. Ranying Hattala Langit merupakan sang pencipta yang melalui Sangiang (Dewa) dan Kemeluk (Dewi) menciptakan alam semeta beserta isinya (Patianom dan Ulaen, 1992:34). Masyarakat Dayak juga mempercayai Tuhan Jata yang dianggap memiliki sifat-sifat kewanitaan seperti lemah lembut, peramah, pengasih, dan suka damai (Ugang melalui Bungas, 2012). Pengaduan pada Ranying Hattala Langit dan Jata dilakukan Tambi ketika menemui Ulin telah berubah dan lebih percaya pada pendatang yang mengimingimingi uang dan barang-barang modern.

Menurut Hermogenes Ugang (melalui Bungas, 2012), masyarakat Dayak memiliki kepercayaan bahwa di alam sekitar terdapat rohroh yang berkeliaran. Dalam cerita bersambung "Ulin" ada beberapa roh yang disebutkan oleh Tambi, seperti roh leluhur yang bisa dipanggil dengan menebarkan beras merah-kuning dan roh penunggu sungai yang telah mengambil nyawa Atei (anaknya) dalam kecelakaan kapal.

Berbeda dengan suku Dayak dan Seasea, suku Bajo memiliki kepercayaan yang disyaratkan kepada laut, di antaranya adalah samauda atau ilmu guna-guna yang disyaratkan kepada laut dan mantra. Ketika Toby Sparks, laki-laki bule, akan melakukan perjalanan naik leppa, Mbo Nuni berpesan agar Toby menyiapkan dua hal penting, yaitu perahu yang bagus dan cara melaut yang baik serta mantra. Mantra akan membuat orang bertahan selama di laut. Hal ini dibuktikan dengan munculnya panas tinggi dengan bentol-bentol di badan Toby Sparks karena ia tidak membaca mantra ketika menias kayu untuk membuat leppa. Ia pun sembuh ketika Mbo Nuni yang menguasai mantramantra dan dapat berbahasa dengan Raja Laut mengobatinya dengan kekuatan mantra.

Orang Bajo meyakini bahwa di dalam laut terdapat dewa laut yang menjadi penguasa atasnya yang disebut dengan culture hero. Dewa itu baik dan menjadi penolong bagi manusia, namun ia juga bisa murka dan memberi bencana. Keselamatan orang Bajo tergantung dari sikap dan tutur yang ditampilkannya ketika sedang berada di laut. Karena itu, mereka memberikan puji-pujian yang ditujukan pada dewa laut beserta para penghuni laut lainnya dalam bentuk mantra agar mereka mendapatkan kemudahan 
dan dijauhkan dari kesulitan. Pengetahuan mengenai mantra yang ditunjang dengan keahlian melaut membuat mereka tampil sebagai "raja laut". Orang Bajo menggunakan mantra dari mulai berangkat hingga pulang (Uniawati, 2007).

Sementara itu, suku Seasea percaya pada mitos, di antaranya adalah mitos Pau Kinolot dan Boloki Seasea. Istilah Pau Kinolot berarti suku yang gemar menyembelih kepala manusia (Alwi, 2010). Dalam cerita bersambung "Sebelum Hujan di Seasea" kebiasaan ini disesali oleh Farina. Farina menganggap hal inilah yang menyebabkan kampung Seasea tidak pernah bisa menyelesaikan masalah air yang selama ini menimpanya.

Suku Seasea juga mempercayai adanya mitos Boloki Seasea (perempuan pertama suku Seasea) yang menghilang di Kaukes. Kaukes pun dianggap sebagai tempat yang sakral, sekaligus sebagai penanda datangnya musibah, melalui penanda bunyi gong yang sebenarnya secara kasat mata gong itu tidak ada (Aladjae, 2012b:17).

Dalam sistem pemerintahan, Seasea merupakan sebuah lipu. Istilah lipu merupakan unit paling kecil setingkat desa sekarang. Istilah lipu merupakan warisan pemerintahan Kerajaan Banggai dahulu. Setiap lipu Lipu dipimpin oleh perangkat adat yang disebut Tonggol atau kepala suku. Tonggol ini diakui sebagai pemimpin dalam struktur masyarakat dan diakui sampai sekarang oleh komunitasnya. Sebagai bagian penting kerajaan Banggai, Tonggol juga merupakan bagian dari perangkat kerajaan di tingkat paling bawah (Alwi, 2010). Dalam cerita bersambung "Sebelum Hujan di Seasea", Tonggol berperan sebagai pelindung dan pelaksana hukuman. Peran Tonggol sebagai pelindung tampak pada permintaan Farina pada Malika untuk menyelamatkan Sima, anaknya, ke rumah Tonggol. Saat itu Farina sedang disiksa oleh Mikus, suaminya, dengan tangan ditali. Ketika Malika datang, Farina memintanya melepas tali dan membawa anaknya ke rumah tonggol. Upaya ini dilakukan oleh Farina untuk meminta perlindungan pada Tonggol dari kekerasan dan penyiksaan suaminya. Sementara itu, perang Tonggol sebagai pelaksana hukuman tampak pada memberikan hukuman pada Habaku yang mencuri tembakau.
Tembakau memang menjadi barang mahal bagi suku Seasea karena mereka memiliki kebiasaan merokok sebagai salah satu hiburan. Umur dan jenis kelamin tidak membatasi mereka untuk merokok (http://jalan2.com). Dalam cerita, Farina, Mikus, dan Martina juga digambarkan memiliki kebiasaan merokok dengan tembakau yang dilinting dengan daun pisang ini.

Suku Seasea memiliki kesenian tradisional berupa seruling yang iramanya khas. Ritmenya datar dan sesekali menukik tajam (Alwi, 2010). Dalam cerita "Sebelum Hujan di Seasea", Farina sering memainkan alat musik ini untuk menidurkan anaknya.

\section{Interaksi Budaya dengan Pendatang da- lam Tiga Cerita Bersambung Pemenang Sayembara Mengarang Majalah Femina 2012}

Pendatang dalam tiga cerita bersambung pemenang sayembara manulis majalah Femina tahun 2012 memiliki wujud yang berbeda-beda. Pendatang pada cerita bersambung "Ulin" adalah perusahaan yang mengambil hasil hutan milik suku Dayak. Pendatang pada cerita bersambung "Rumah Perahu" adalah penulis yang peduli pendidikan dan fotografer asing yang peduli lingkungan. Sementara itu, pendatang pada cerita bersambung "Sebelum Hujan di Seasea" adalah LSM yang bergerak di bidang sanitasi dan air.

Pendatang yang berupa perusahaan kayu masuk ke dalam masyarakat Dayak masuk melalui penduduk asli Dayak, yaitu Mina. Mina adalah kaki tangan pendatang yang paling berpengaruh pada perubahan sikap Ulin dan suaminya. Sejak kedatangan Mina, banyak orang Dayak di kampungnya berubah. Tambi menganggap Mina sebagai penyebab lunturnya nilai-nilai Dayak yang telah diwariskannya kepada Ulin.

Melalui tokoh Mina. pengaruh modernisasi masuk pada diri Ulin dan orang-orang Dayak. Hal ini tampak pada munculnya barangbarang modern seperti vetsin, obat penurun panas, daster batik, majic com atau penanak nasi, bedak pemutih, yang menggeser potensi alam yang selama ini digunakan oleh masyarakat Dayak. Sebagaimana disebutkan di atas, 
masyarakat Dayak memiliki ketergantungan yang tinggi pada alam. Baginya, alam sudah sangat cukup menyediakan bumbu dapur, obat, kayu untuk menanak, dan sebagainya. Karena itu, modernisasi membuat ornag menjadi meninggalkan alam dan tidak setia lagi pada alam. Justru yang terjadi mereka menjadi musuh alam karena mereka dianggap merusak alam yang telah memberikan penghidupan.

Pengaruh modernisasi yang dibawa Mina juga tampak pada uang yang selalu diiming-imingkannya pada Ulin. Uang memang menjadi tuntutan bagi modernisasi. Uang menjadi sarana memenuhi kebutuhan hidup. Keyakinan bahwa uang akan membuat hidup lebih mapan dan bahagia telah merasuk ke dalam diri Ulin sehingga ia menyarankan suaminya, Andau, untuk bekerja di perusahaan kayu.

Sementara itu, pendatang pada cerita bersambung "Rumah Perahu" adalah seorang penulis yang memiliki latar belakang sarjana yang memiliki kepedulian dengan masalah pendidikan, yaitu Yarima, dan seorang fotografer asing yang peduli dengan lingkungan, yaitu Toby Sparks. Sebagaimana ditulis di depan, masyarakat suku Bajo merasa superior dengan kemampuannya melaut. Hal ini diperkuat dengan pendapat Ahimsa-Putra (melalui Uniawati, 2007) dari hasil analisis kehidupan sosial-budaya masyarakat suku Bajo tergambar bahwa secara psikologis mereka merasa lebih pandai dari masyarakat yang ada di darat karena mampu mengarungi samudera yang besar dan dalam sekalipun. Namun, di sisi lain mereka merasa inferior karena orang-orang darat mempunyai peradaban dalam hal ilmu pengetahuan dan teknologi yang lebih dibanding mereka yang hanya bergelut di laut. Oleh karena itu, sangatlah beralasan jika muncul persepsi di luar masyarakat suku Bajo bahwa suku Bajo adalah masyarakat terasing, terbelakang, dan tertutup.

Pendapat ini sejalan dengan rendahnya tingkat pendidikan suku Bajo yang tinggal di laut yang tergambar dalam cerita bersambung "Rumah Perahu". Yarima datang dari Makasar dan tinggal di Kalupapi, selain untuk menulis juga untuk mengabdikan diri sebagai guru di sekolah kolong "Mata Tujuh" untuk anak-anak suku Bajo yang orang tuanya tidak mampu menyekolahkan anaknya.
Dalam cerita ini, muncul juga tokoh Toby Sparks, seorang fotografer asing berkulit putih yang datang berkeliling Indonesia dengan didanai perusahaan sponsor. Kedatangannya menjadi perhatian ibu-ibu suku Bajo. Dalam perkembangan cerita, lelaki kulit putih ini banyak berinteraksi dengan Mbo Nuni untuk membuat leppa atau perahu beratap khas Bajo. Interaksi budaya terjadi ketika badannya bentolbentol dan demam sehabis menias karena tidak membaca mantra. Ia sembuh setelah Mbo Nuni mengobatinya dengan mantra-mantra yang ditujukannya ke laut. Orang-orang luar suku Bajo semula tidak mempercayainya, tetapi hasil kekuatan mantra yang mereka saksikan membuat mereka percaya dan memahami cara hidup orang-orang Bajo.

Pendatang dalam cerita bersambung "Sebelum Hujan di Seasea" adalah LSM yang bergerak di bidang sanitasi dan air. LSM ini melaksanakan berbagai program terkait sanitasi dan air, seperti pembagian WaterGuard (penjernih air) di daerah Bulagi, penyediaan air siap minum dari tampungan air hujan di daerah Sosom, dan program sanitasi di desa Buon di mana setelah program itu berjalan, banyak warga membangun jamban. LSM ini melaksanakan berbagai program untuk membantu masyarakat dalam penyediaan air bersih dan membangun kesadaran akan pentingnya sanitasi di daerahdaerah yang bermasalah.

Seasea dalam cerita merupakan salah satu daerah yang menjadi sasaran observasi LSM ini. Suku ini memiliki masalah kesulitan air. Karena tidak ada air, suku ini hidup dari air embun yang mereka kumpulkan setiap pagi. Hal ini disebabkan oleh kemarau yang sangat panjang. Selama delapan bulan di Seasea tidak turun hujan. Hal ini diketahui dari cerita Malika ketika Mikus membunuh Farina. Saat darah Farina memercik, hujan turun lebat sebagaimana tampak dalam kutipan, "Itu adalah hujan pertama setelah delapan bulan kemarau panjang di tanah ini" (Aladjae, 2012b:44).

Selain kemarau, kesulitan air dimungkinkan disebabkan oleh struktur tanah. Daerah puncak Peling memiliki jenis topograpi berbukit di mana tanahnya mempunyai kandungan kapur yang sangat tinggi. Struktur tanah ini menyebabkan tidak ada sungai dan mata air yang dapat 
dijadikan sarana untuk menyimpan air (Alwi, 2010).

Sementara itu, suku Sea-sea ini memiliki cara yang unik untuk mencari air untuk kebutuhan sehari-hari. Suku ini menganyam dedaunan dan diletakkan di batang pohon yang besar. Dari anyaman daun ini tertampunglah air hujan dan embun yang sedikit demi sedikit menetes ke sebuah wadah yang sudah disiapkan sebelumnya. Wadah berupa tembikar ini terbuat dari tanah liat. Suku Seasea menamakan tempat penampung air ini sebagai gumbang (Aladjae, 2012b:16 dan http://jalan2.com).

\section{Respon Tokoh terhadap Kehidupan Multikultural dalam Tiga Cerita Bersam- bung Pemenang Sayembara Mengarang Majalah Femina 2012}

Kehadiran pendatang dalam tiga cerita bersambung pemenang sayembara mengarang majalah Femina tahun 2012 ini menyebabkan adanya interaksi budaya yang menciptakan kehidupan multikultural. Tokoh-tokoh cerita memberi respon yang beragam, yaitu menentang atau melawan, terpengaruh, dan bekerja sama. Respon tokoh terhadap kehidupan multikultural ini dijabarkan sebagai berikut.

Cerita bersambung "Ulin" mengangkat masyarakat Dayak sebagai latar cerita. Kondisi masyarakat Dayak yang diangkat dalam cerita ini terdiri dari dua bagian, yaitu masyarakat Dayak yang masih memegang adat secara kuat dan masyarakat Dayak yang telah dipengaruhi oleh modernisasi yang dibawa oleh pendatang. Dua kategori masyarakat ini hadir dalam cerita untuk membangun konflik.

Masyarakat Dayak yang masih memegang adat yang kuat diwakili oleh tokoh Tambi, nenek Ulin. Sebagai orang Dayak, Tambi sejak kecil selalu mendidik Ulin dengan nilai-nilai Dayak. Tambi mewariskan ilmu dan keterampilan berladangnya kepada Ulin, seperti menabur benih, membersihkan ikan, berburu, mengenali pertanda alam, dan sebagainya. Selain itu, Tambi juga mewariskan dongeng-dongeng dan nasihatnasihat yang akan membuatnya semakin kuat sebagai orang Dayak. Semua itu dilakukan Tambi demi mewujudkan harapannya mendidik Ulin menjadi gadis Dayak yang kuat, seperti anak enggang putri naga, yang berharga bagi masa depan. Namun, ia mendapat pengkhianatan ketika di masa besarnya, Ulin justru mengingkari ajaran-ajaran yang telah ditanamkannya. Tambi merasa hal ini seperti senjata makan tuan.

Burung enggang juga digunakan Tambi untuk mensifati Andau, suami Ulin. Semasa Ulin masih kecil, Tambi sering mendongeng tentang kisah sepasang burung enggang. Burung enggang ini selalu bersama dalam membangun generasi. Demi anak-anaknya, enggang betina akan mengurung diri dalam sarang, lalu enggang jantan akan menutupinya dengan lumpur. Enggang jantan juga membuat celah untuk memberikan makanan pada enggang betina. Tambi pun mengandaikan pasangan Ulin dan Andau ini seperti sepasang burung enggang yang memiliki kesetiaan dan pengorbanan seperti itu. Namun, akhirnya ia harus kecewa karena Ulin dan Andau tidak memenuhi harapannya. Mereka terpengaruh oleh janji-janji para pendatang yang merusak alam. Ulin juga menyarankan Andau untuk bekerja di perusahaan kayu. Namun, akhirnya Andau pergi meninggalkan Ulin tanpa kabar. Selain pada adat dayak, Andau juga tidak setia lagi pada Ulin.

Menurut Maunati (2004:180), bagi masyarakat Dayak, burung enggang merupakan simbol kepemimpinan, kemuliaan, dan kemakmuran. Burung enggang memiliki bulu-bulu yang besar dan indah melambangkan pemimpin yang dikagumi rakyatnya. Burung enggang suka hinggap di pohon-pohon tinggi dan mengeluarkan suara indah yang melambangkan suara pemimpin yang didengar rakyatnya. Burung enggang memiliki sayap lebar yang melambangkan pemimpin yang melindungi rakyatnya. Burung enggang memiliki ekor yang panjang yang melambangkan ketentraman dan kemakmuran bagi semua orang.

Masyarakat Dayak dikenal memiliki konflik eksternal dengan pendatang, terutama dengan suku Madura. Menurut Maunati (2004: 3), beberapa pakar berpendapat bahwa marjinalisasi ekonomi yang sudah lama dialami oleh masyarakat Dayak merupakan sumber utama konflik tersebut. Khan (melalui Maunati, 2004:4) menyatakan bahwa yang dibutuhkan oleh perekonomian global dari mereka adalah tanah dan sumber-sumber daya yang mereka miliki. Hal inilah yang dirasakan oleh Tambi. 
Tambi merasa resah ketika di sekitarnya mulai masuk perusahaan kayu yang menggusur ladang-ladang mereka. Keresahan itu bahkan ia rasakan sejak pertama kali para pendatang ini masuk ke kampungnya. Semula mereka datang baik-baik, tetapi tidak diam-diam mereka mulai mengambil sumber alam mereka. Mereka mendatangkan mesin-mesin besar untuk mengambil kayu-kayu di hutan.

Selanjutnya, para pendatang itu semakin nekat. Mereka bisa mempengaruhi pengurus adat sehingga mereka bisa leluasa mengambil sumber alam mereka tanpa ada hukuman sedikit pun. Harta milik suami Tambi berupa tanah, kebun karet, durian, dan rumpun rotan juga ikut diambil oleh para pendatang ini. Ketidakadilan ini membuatnya sakit dan berakhir dengan kematian.

Rasa sakit hati pada para pendatang itu sampai juga pada Atei, anak sulung Tambi yang merupakan ayah Ulin. Ia melakukan perlawanan dengan caranya sendiri. Ia mendekat pada pendatang dengan bekerja sebagai penarik kapal dengan harapan bisa menghancurkannya dari dekat. Namun, belum lama ia bekerja, kapalnya terbalik dan Atei menjadi satu-satunya korban yang meninggal dunia.

Dengan uraian ini, kebencian Tambi pada pendatang sebenarnya sudah berlangsung lama. Jika sekarang para pendatang ini akan mengambil cucu-cucunya, Tambi tidak akan pernah rela. Dalam benak Tambi, para pendatang ini memiliki kecerdikan yang luar biasa untuk menyingkirkan pribumi dan mengambil aset-aset mereka. Kecerdikan itu digambarkan melalui perkataan Tambi, "Kupikir, orang-orang perusahaan sudah tahu bagaimana cara menyuap para roh. Jika benar demikian, sungguh tidak salah aku memusuhi mereka." Bagi masyarakat Dayak, roh memiliki kedudukan sebagai Tuhan. Secara hiperbolis, Tambi mengungkapkan hingga Tuhan pun bisa disuap, apalagi manusia. Suap ini dalam praktiknya membuat para pendatang menjadi kebal hukum sehingga mereka bisa mengambil tanah tanpa harus membayar denda adat atau mendapat hukuman.

Keyakinan bahwa pendatang akan melenyapkan dan menyakiti masyarakat Dayak ini semakin diperkuat dengan nasib tragis yang menimpa Ulin. Suaminya bekerja pada perusahaan dan tidak pernah pulang. Di tempat kerja, ternyata suami Ulin berselingkuh dengan perempuan yang bekerja di situ dan mengalami kecelakaan yang membuatnya menjadi cacat.

Berbeda dengan suku Dayak yang terpengaruh dan melakukan perlawanan dengan pendatang, suku Bajo dan Seasea dalam cerita bekerja sama dengan baik dengan para pendatang. Yarima, seorang penulis yang peduli dengan masalah pendidikan, dapat membaur dengan suku Bajo dan terlibat dalam menyelesaikan masalah suku Bajo. Sebagaimana disebutkan di atas, Yarima mengelola sekolah darurat untuk anak-anak Bajo yang tidak mampu.

Selain memberi pengaruh lewat pendidikan, Yarima juga hadir sebagai tempat diskusi permasalahan Bajo melalui tokoh Tonio, orang Bajo asli. Hal tampak ketika Tonio mendiskusikan rencana pemerintah untuk merelokasi pemukiman Bajo dari laut ke darat agar dapat hidup dengan layak.

Sementara itu, dalam cerita bersambung "Sebelum Hujan di Seasea", interaksi LSM yang diwakili oleh Malika dan Gilang dengan suku Seasea belum terjadi secara intensif. Pertemuan mereka terjadi di akhir cerita. Mereka terlibat dalam pertengkaran antara Mikus dan Farina, sepasang suami istri dari suku Seasea yang hidup tidak harmonis.

Puncak pertengkaran antara Farina dan Mikus awalnya terjadi karena masalah gumbang. Farina meminta Mikus ke rumah Dominggus untuk memesan gumbang yang akan ditukar dengan sondang. Namun, Mikus tidak melakukannya dan hanya duduk-duduk santai di rumah seharian, sementara Farina bekerja seharian tidak pernah istirahat. Rasa capeknya membuatnya ia tidak tahan untuk menegurnya. Mikus pun marah. Ia menampar, menarik rambut, bahkan mengancam Farina dengan sondang atau pisau panjang. Pertengkaran yang sering dialami Mikus dan Farina menjadi tidak seimbang karena perlindungan Martina, ibu Mikus, yang selalu membelanya dan mendudukkannya di posisi aman dan selalu benar, sedangkan $\mathrm{Fa}-$ rina selalu salah.

Pertemuan Farina dengan Malika dan Gilang terjadi di jalan saat malam hari. Farina kemalaman pulang dari pasar. Malika dan Gilang menawarkan tendanya agar Farina dan anaknya 
bisa beristirahat. Pertemuan berikutnya terjadi ketika Malika dan Gilang sampai di perkampungan suku Seasea. Mereka mendengar teriakan perempuan. Teriakan itu ternyata suara Farina yang tengah disiksa suaminya. Mengetahui Malika datang, Farina memintanya menyelamatkan anaknya ke rumah tonggol, kepala suku. Pada akhir cerita, Farina pun mati di tangan Mikus.

Kematian Farina di tangan Mikus, suaminya, dalam cerita ini menguatkan identitas suku Seasea sebagai Pau Kinolot, yaitu suku yang gemar menyembelih kepala manusia. Selain itu, kematian ini juga menguatkan adanya mitos adanya Boloki Seasea (perempuan pertama suku Seasea) menghilang. Kaukes ini bagi suku Seasea adalah penanda datangnya musibah (Aladjae, 2012b:17). Namun, dalam konteks kematian Farina, hal ini menjadi berkah karena hujan kembali turun setelah delapan bulan kemarau panjang. Hal ini bisa jadi isyarat bahwa titik puncak penderitaan manusia, dalam hal ini perempuan, telah membuat alam bereaksi.

\section{PENUTUP}

Tiga cerita bersambung pemenang sayembara mengarang Femina 2012 mengangkat kehidupan suku Dayak di Kalimantan, serta suku Bajo dan suku Seasea di Sulawesi. Ketiga suku ini memiliki budaya yang khas. Judul cerita yang diangkat memiliki keterkaitan dengan kondisi sosial budayanya. Istilah dalam judul cerita bersambung "Ulin" merupakan nama sebuah pohon yang kuat yang biasa dipakai untuk tiang rumah dalam masyarakat Dayak. Istilah dalam judul cerita bersambung "Rumah Perahu" merupakan leppa yang biasa digunakan oleh Suku Bajo untuk melaut. Istilah dalam judul cerita bersambung "Sebelum Hujan di Seasea" merupakan kemarau panjang dan kejadian dramatis sebelum hujan turun di suku Seasea.

Ketiga cerita ini menampilkan pendatang dalam sukunya, yang sekaligus menunjukkan adanya kehidupan multikultural. Cerita bersambung "Ulin" menampilkan pendatang berupa perusahaan kayu yang mengambil keuntungan dari alam suku Dayak. Cerita bersambung "Rumah Perahu" menampilkan pendatang berupa penulis yang peduli dengan masalah pendidikan dan mendirikan sekolah darurat untuk anak-anak Bajo yang tidak mampu. Selain itu, cerita ini juga menampilkan seorang fotografer asing berkulit putih yang memiliki kepedulian dengan masalah lingkungan. Sementara itu, cerita bersambung "Sebelum Hujan di Seasea" menampilkan pendatang berupa LSM yang bergerak di bidang sanitasi dan air.

Tokoh dalam ketiga cerita bersambung tersebut menunjukkan respon yang berbedabeda dengan pendatang yang masuk ke dalam suku mereka. Suku Dayak dalam cerita bersambung "Ulin" menunjukkan sikap terpengaruh dan melawan. Mereka yang terpengaruh adalah orang-orang Dayak yang tergiur dengan uang dan barang-barang modern, seperti penanak nasi listrik, lemari es, pemutih kulit, baju , dan sebagainya. Mereka yang melawan adalah orang-orang Dayak yang merasa alamnya dicuri oleh pendatang yang berdampak pada adanya kesenjangan ekonomi. Sementara itu, suku Bajo dan Seasea dalam cerita bersambung "Rumah Perahu" dan "Sebelum Hujan di Seasea" menunjukkan sikap yang kooperatif atau mau bekerja sama untuk menyelesaikan permasalahan mereka. Suku Bajo kooperatif dengan pendatang yang membantunya mengatasai masalah rendahnya tingkat pendidikan. Suku Seasea kooperatif dengan pendatang yang mau membantunya menyelamatkan anak ke kepala suku dari kekejaman suami.

\section{DAFTAR PUSTAKA}

Ahimsa-Putra, Heddy Shri. 2006. Strukturalisme Levi-Strauss Mitos dan Karya Sastra. Yogyakarta: Kepel

Aladjae, Erni. 2012a. "Rumah Perahu". Diakses dari www.femina.co.id pada 1 Agustus 2013

2012b. "Sebelum Hujan di Seasea". Koleksi pribadi Erni Aladjae versi pdf.

Alwi, Andi F. 2010. "Menjejaki Komunitas Suku Seasea di Dataran Tinggi Pulau Peling”. 10 November 2010. Diakses dari http://katulutulu.blogspot.com pada 1 November 2013.

Bungas, Lery. 2012. Makna Ritual Nyadiri bagi Kehidupan Suku Dayak ngaju. Tesis. Program Pascasarjana Magister Sosiologi Agama Universitas Kristen Satya Wacana diakses dari http://repository. 
library.uksw.edu pada 10 November 2013

Femina. 2012. "Penguman Pemenang Sayembara Cerber Femina 2012". No.17/XL 28 April-4 Mei 2012

http://jalan2.com. 2012. "Melongok Banggai Kepulauan”. Diakses pada 1 November 2013.

Mahayana, Maman S. 2008. "Menuju Sastra Indonesia dalam Perspektif Multikulturalisme". Diakses dari http://mahayanamahadewa.com pada 25 April 2013.

Maunati, Yekti. 2004. Identitas Dayak: Komodifikasi dan Politik Kebudayaan. Yogyakarta: LkiS.

Patianom, J.I.D dan Ulaen, H.J. 1992. Sejarah Sosial Palangka Raya. Jakarta: Depdikbud Direktorat Sejarah dan Nilai Tradisional Proyek Inventarisasi dan Dokumentasi Sejarah Nasional.
Purwana, Bambang H. Suta. 2005. "Babad Babat Sawit di (Hutan) Kalimantan barat" dalam Ingat(!)an Hikmat indonesia Masa Kini Hikmah masa Lalu Rakyat (Budi Susanto ed.). Yogyakarta: Kanisius.

Thaif, Anindita Siswanto. 2012. "Ulin". Diakses dari www.femina.co.id pada 1 Agustus 2013.

Uluk, Asung, Made Sudana, Eva Wollenberg. 2001. Ketergantungan Masyarakat Dayak terhadap Hutan di Sekitar Taman Nasional Kayan Mentarang. CIFOR: Jakarta.

Uniawati. 2007. Mantra Melaut Suku Bajo: Interpretasi Semiotik Riffaterre. Tesis Pasca Sarjana Universitas Diponegoro Semarang. Diakses dari http://eprints. undip.ac.id/17573/1/Uniawati.pdf pada 10 November 2013. 